\title{
Childhood Peutz-Jeghers syndrome: Diversity of clinical features and complications, and literature review
}

\author{
Mark R Oliver mbBs, R Brent SCOTt mDCM, Robin C ECCles mD, CYNTHiA TREvEnen mD, \\ JONATHON B MEDDINGS MD, STEVEN R MARTIN MD
}

MR Oliver, RB Scott, RC ECCles, C TREVEnen, JB MEdDings, SR MARTIN. Childhood Peutz-Jeghers syndrome: Diversity of clinical features and complications, and literature review. Can J Gastroenterol 1994;8(4): 253-256. This case report of a six-year-old child with Peutz-Jeghers syndrome illustrates the potential diversity of presenting gastrointestinal symptoms and signs including hematemesis, obstruction and recurrent intussusception. Endoscopy was useful in assessment, while endoscopic polypectomy and surgical resection were both necessary for management. The literature is reviewed and the possible role that this syndrome may have in the development of both gastrointestinal and nongastrointestinal tumours is highlighted.

Key Words: Intussusception, Malignancy, Peutz-Jeghers syndrome

\section{Syndrome de Peutz-Jeghers chez l'enfant : diversité des} caractéristiques cliniques et des complications et survol de la littérature

RÉSUMÉ : Ce rapport de cas porte sur un enfant de six ans atteint du syndrome de Peutz-Jeghers et illustre la diversité potentielle des symptômes et signes gastro-intestinaux qui se manifestent, y compris l'hématémèse, l'obstruction et l'intussusception récurrente. L'endoscopie s'est révélée utile pour évaluer la situation, alors que la polypectomie endoscopique et la résection chirurgicale ont toutes deux été nécessaires en thérapeutique. La littérature est passée en revue et le rôle possible de ce syndrome dans le développement des tumeurs gastrointestinales et autres est souligné.

Departments of Medicine, Pathology, Pediatrics and Surgery, Alberta Children's Hospital and University of Calgary, Calgary, Alberta

Correspondence and reprints: Dr R Brent Scott, Department of Pediatrics, University of Calgary, Health Science Centre, 3330 Hospital Drive NW, Calgary, Alberta T2N 4N1.

Telephone (403) 220-4556, Fax (403) 283-3028

Received for publication February 7, 1994. Accepted February 8, 1994
Deutz-jeghers syndrome was first described by Peutz (1) in 1921 and characterized by Jeghers et al (2) in 1949. It is a relatively rare syndrome transmitted as an autosomal dominant disorder and characterized by gastrointestinal polyposis and mucocutaneous pigmentation. The polyps are characteristically hamartomas and can occur in the stomach, small intestine and colon. Though generally considered to be a benign condition (3), significant morbidity and mortality are related to recurrent intussusception, as evidenced by several reviews $(4-7)$ and the patient described in this report. In addition, both case reports and reviews from large polyposis registries provide increasing evidence to suggest that there is a link between this syndrome and the development of not only gastrointestinal tumours (7-11) but also - perhaps more significantly - a variety of nongastrointestinal tumours $(7,10,11)$. This link raises questions about appropriate surveillance and long term follow-up of these patients. This case report describes a young child with complications of Peutz-Jeghers syndrome and reviews the literature with 
regards to the natural history and the management of these complications.

\section{CASE PRESENTATION}

A six-year-old girl presented with a $24 \mathrm{~h}$ history of forceful, recurrent, bilestained emesis which progressed to frank hematemesis and the loss of approximately $300 \mathrm{~mL}$ of blood. The vomiting had been preceded by a vague left upper quadrant abdominal discomfort which was relieved by the emesis. There were no other associated gastrointestinal or systemic symptoms. A previous episode of bilious emesis and hematemesis two years before settled with conservative management and had not been investigated. Family history was noncontributory. Clinical evaluation showed a six-year-old who appeared well but pale. Her vital signs were stable and the rest of the physical examination was unremarkable.

Hemoglobin was $93 \mathrm{~g} / \mathrm{L}$, with normal red blood cell morphology, white blood cell count and platelet count. Other laboratory investigations including prothrombin and activated partial thromboplastin times, electrolytes, urea, creatinine, liver function tests, albumin, protein and urinalysis were normal.

Initial management included stabilization with replacement of fluid and electrolyte losses. An upper gastrointestinal endoscopy was performed up to and including the second part of the duodenum. Five sessile, nonulcerated polyps were identified on the greater curvature of the stomach, and a large pedunculated polyp ( $2 \mathrm{~cm}$ in diameter) present in the duodenal bulb was both ulcerated and bleeding. Biopsies of the gastric polyps were taken and were later identified as hamartomas.

The duodenal polyp was removed endoscopically, as was a hamartoma with the characteristic histological features of Peutz-Jeghers syndrome. Following endoscopy the patient was re-examined and found to have six small pigmented lesions on the mucous membranes of her lower lip which were only visible when the lip was everted. She had no cutaneous lesions.

Three weeks after polypectomy, while the patient was still asympto- matic, a barium swallow with small bowel follow-through and a double contrast barium enema were performed to evaluate the extent of involvement of the gastrointestinal tract. The former study demonstrated an ileocolonic intussusception without significant obstruction. The barium enema also demonstrated an intussusception which began in the midascending colon and was reduced, leaving a filling defect of $3 \mathrm{~cm}$ in diameter in the terminal ileum. No other changes suggestive of polyps were identified. A colonoscopy was scheduled to remove the ileal polyp.

At colonoscopy a small rectal polyp was identified and removed. The remainder of the colon and cecum appeared normal. The terminal ileum was entered; just beyond the ileocecal valve a large pedunculated polyp filled the lumen and was partially obscured by two broad-based polyps that were ulcerated and had a nodular appearance that extended into the adjacent mucosa. The appearance was similar to, or suggestive of, an adenocarcinoma. Endoscopic polypectomy was deemed unsafe due to the large size of the lesions. Biopsies were consistent with hamartomas, with no evidence of adenomatous or carcinomatous changes. Because of the risk of recurrent intussusception and persistent concern about malignancy it was decided to proceed with operative resection.

At surgery, it appeared that polyps in the terminal ileum had acted as a lead point and once again caused an intussusception to the midascending colon. This was easily reduced, and there was no evidence of vascular compromise. It was interesting to note that the patient had not complained of any symptoms preoperatively. Approximately $10 \mathrm{~cm}$ of terminal ileum including the ileocecal valve, the cecum and the appendix were removed. Palpation of the remaining small intestine did not disclose further polyps. The patient had an uneventful postoperative period. The gross pathological description of the opened resected ileum and cecum revealed a large polypoid mass $3.5 \mathrm{~cm}$ in diameter attached to the ileal mucosa by a short $1 \mathrm{~cm}$ diameter stalk approximately $2 \mathrm{~cm}$ proximal to the ileocecal valve. In the mucosa around the larger polyp there were multiple small nodular projections measuring up to $5 \mathrm{~mm}$ in diameter. Histological sections from the large polyp revealed elongated villiform projections of ileal mucosa with irregularly distributed mature glandular structures separated by ramifying bundles of smooth muscle. Many of the glandular structures contained inspissated eosinophilic secretions intermingled with neutrophils. The inflammatory process extended from some of these distended glands into the adjacent lamina propria and muscular stroma. There was no evidence of malignancy. Two of the smaller ileal nodules were histologically similar to the large hamartomatous polyp; the rest were hyperplastic lymphoid follicles with prominent germinal centres.

The patient has remained well nine months after operation. Her relatives, parents and younger sibling are asymptomatic and demonstrate none of the clinical features of this syndrome, sug. gesting that this girl's disease may be secondary to a new mutation.

\section{DISCUSSION}

Patients with Peutz-Jeghers syndrome manifest a variety of symptoms that depend upon the site, size and number of polyps in the gastrointestinal tract, and can range from anemia, vomiting, melena and hematemesis to obstruction due to an intussusception. The patient described in this report not only demonstrated many of these symptoms but was also shown to have the unusual entity of an asymptomatic intussusception on two occasions. It is well recognized that in Peutz-Jeghers syndrome intussusceptions may not cause complete obstruction and can be transient (5), but they are usually associated with symptoms (4-7). It is plausible that this patient had a 'loose' intussusception and hence did not yet have any symptoms related to ischemia or obstruction.

The complication of intussusception is by far the most common cause of significant morbidity and mortality related to this disorder. Dormondy $(4,5)$ 
reported that in a series of 21 patients with Peutz-Jeghers syndrome, 14 required 33 laparotomies over a follow-up period of three to 60 years. Spigelman et al (12) noted that repeat laparotomy for intussusception was common in patients with Peutz-Jeghers syndrome; they reported that the procedure was performed on 54 occasions in 23 patients. A 49-year follow-up of 12 members of a family affected by PeutzJeghers syndrome reported that one patient developed short bowel syndrome (dependent on parenteral nutrition) and three others died as teenagers as a consequence of the complications of intussusception (7).

Conventional methods used to reduce the incidence of repeat laparotomy and complications related to repeated intussusception include palpation and transillumination at the time of surgery (the former was used in this patient). More recently it has became apparent that there may be a role for intraoperative enteroscopy in patients (including children) with PeutzJeghers syndrome who have recurrent symptoms suggestive of intussusception or extensive polyposis documented radiologically $(12,13)$. The procedure has the advantage of accurately assessing the extent of small intestinal involvement, permitting the removal of smaller polyps by endoscopic polypectomy and guiding the surgeon to those polyps that must be removed by enterotomy. In the short term, intraoperative enteroscopy appears to reduce the frequency of subsequent repeat intussusception and may prove to reduce the incidence of potential complications such as short bowel syndrome. However, it is not without risks such as torsion of the mesentery or overdistension of the gut.

Though the patient described in this report did not have clinical or histological evidence of either gastrointestinal or nongastrointestinal cancer, there are several reports of patients with Peutz-Jeghers syndrome who have been afflicted with a wide variety of malig. nant gastrointestinal tumours involving the stomach, small intestine and colon, and nongastrointestinal malignancies of the cervix, breast, ovary, tes- tes and thyroid $(8-11)$. The true incidence of malignancy in this condition is unknown; however, recent reports from Giardello et al (10) and Spigelman et al (11) utilized strict criteria for the definition of Peutz-Jeghers syndrome, and in their series of patients have shown a significantly increased incidence of both gastrointestinal and nongastrointestinal tumours. Giardello and colleagues reported that in 31 individuals with Peutz-Jeghers syndrome (mean age at diagnosis $17 \pm 16$ years, with mean follow-up of $21 \pm 15$ years) malignancy developed in 15: four had gastrointestinal carcinomas, 10 had nongastrointestinal carcinomas and one had multiple myeloma. In addition, adenomatous polyps were found in the stomach and colon in three other patients. The relative risk of developing cancer in their series of patients was 18 times greater than in the general population $(\mathrm{P}<0.0001)$. Spigelman et al (11) reported 72 patients with PeutzJeghers syndrome on the polyposis registry at St Marks Hospital in London, England. Sixteen developed malignancies (nine gastrointestinal and seven nongastrointestinal), of whom all but one died from cancer. The relative risks of death from gastrointestinal cancer and nongastrointestinal cancers were 13 and 9, respectively. Life-table analysis showed that the chance of dying of malignancy was $48 \%$ by 57 years of age.

Despite a degree of selection bias these studies suggest that Peutz-Jeghers syndrome may be a premalignant condition with an increased risk of developing both gastrointestinal and nongastrointestinal cancer. This suggests that the gene locus controlling the development of Peutz-Jeghers syndrome has an important role regulating cellular differentiation and growth in other tissues in addition to those of the gastrointestinal tract. There is evidence that in some cases adenomatous changes in the stomach, small intestine and colon coexist with the benign hamartomatous polyps, suggesting that there may be a progression from hamartoma to adenoma and then to carcinoma $(7,10)$.

Obviously, large long term prospective studies will be required to define the real risk of malignancy accurately. Current literature supports a need for long term surveillance for malignancy. The nature of that surveillance still re. quires a full cost-benefit analysis; however, in the adult female population it should probably include annual breast and gynecological examinations and perhaps mammography, pelvic ultrasound and cervical smears (11). It is suggested that gastrointestinal surveillance include two yearly upper endoscopy, colonoscopy and small bowel follow-through procedures. In patients with polyps greater than $1.5 \mathrm{~cm}$ in diameter, or with polyps and abdominal pain, intraoperative enteroscopy may be useful to reduce the rate of complications of intussusception (11). It is not yet established at what age surveillance should begin. Clearly it is common for patients to present early in the first decade of life with anemia, rectal bleeding, hematemesis, intermittent abdominal pain and vomiting, or intussusception $(4,5,10)$. Giardello and co-workers (10) estimated that the mean interval $( \pm \mathrm{SD})$ between diagnosis of the syndrome and diagnosis of cancer was $25 \pm 20$ years (range one to 64 ), and in Spigelman's series (11) the majority of malignancies was diagnosed in patients in their second and third decades of life. Feminizing gonadal tumours have been described in five prepubertal children as young as age three with PeutzJeghers syndrome. A boy (14) and two sisters (15) had sex cord tumour with annular tubules, and another boy (16) and a girl (17) had Sertoli cell tumour. Thus, even in children, screening should probably include annual physical examination (including a pelvic ultrasound in females) looking for evidence of gonadal enlargement, gynecomastia or precocious puberty.

\section{REFERENCES}

1. Peutz JA. On a very remarkable case of familial polyposis of the mucous membrane, intestinal tract and nasopharynx accompanied by peculiar pigmentation of the skin and mucous membrane. Ned Tijdschr Geneeskd 1921;10:134-46.

2. Jeghers M, McCusick VA, Katz KM Generalized intestinal polyposis and melanin spots of the oral mucosa, lips 
and digits; a syndrome of diagnostic significance. N Engl J Med 1949;241:1031-6.

3. Long JA Jr, Dryfuss JR. The Peutz-Jeghers syndrome: a 39 year clinical and radiological followup report. N Engl J Med 1977;297:1070.

4. Dormandy TL. Gastrointestinal polyposis with mucocutaneous pigmentation (Peutz-Jeghers syndrome). N Engl J Med 1957;256(Pt 1):1093-102.

5. Dormandy TL. Gastrointestinal polyposis with mucocutaneous pigmentation (Peutz-Jeghers syndrome). N Engl J Med 1957;256(Pt 2):1141-90.

6. Bailey D. Polyposis of gastrointestinal tract: The Peutz-Jeghers syndrome. Br Med J 1957;2:433-9.

7. Foley TR, McGarrity TJ, Abt AB. Peutz-Jeghers syndrome: a clinicopathologic survey of the
"Harrisburg family" with a 49 year follow-up. Gastroenterology 1988;95:1535-40.

8. Reid JD. Intestinal carcinoma in the Peutz-Jeghers syndrome. JAMA 1974;229:883-4.

9. Lianos DA, Dozois R, Dahlin D, Bartholomew L. Does Peutz-Jeghers syndrome predispose to gastrointestinal malignancy? A later look. Arch Surg 1981;116:1181-4.

10. Giardello F, Welsh S, Hamilton S, et al. Increased risk of cancer in the Peutz-Jeghers syndrome. N Engl J Med 1987;316:1511-4.

11. Spigelman AD, Murday V, Phillips RKS. Cancer and Peutz-jeghers syndrome. Gut 1989;30:1588-90.

12. Spigelman AD, Thompson JPS, Phillips RKS. Toward decreasing the relaporatomy rate in the Peutz-Jeghers syndrome: the role of preoperative small bowel endoscopy. Br J Surg 1990;77:301-2.

13. Tytgat GNJ, Mathus-Vleiger EMM. Intra-operative endoscopy: technique indications and results. Gastrointest Endosc 1986;32:381-4.

14. Dubois RS, Hoffman WH, Krishman $\mathrm{TH}$, et al. Feminizing sex cord tumor with annular tubules in a boy with Peutz-Jeghers syndrome. J Pediatr 1982;101:568-71.

15. Solh HM, Ramez SA, Najjar SS. Peutz-Jeghers syndrome associated with precocious puberty. J Pediatr 1983;103:593-5.

16. Cantu JM, Rinera H, Ocampo-Campos $\mathrm{R}$, et al. Peutz-Jeghers syndrome with feminizing Sertoli cell tumor. Cancer 1980;46:223-8.

17. Christian CD, McLouglin TG, Cathcart ER, Eisenberg MM.

Peutz-Jeghers syndrome associated with functioning ovarian tumor. JAMA 1964;190:935-8. 


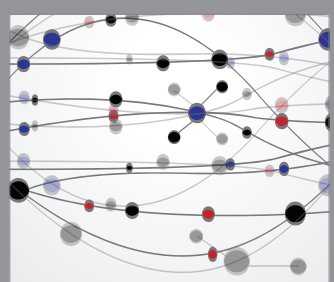

The Scientific World Journal
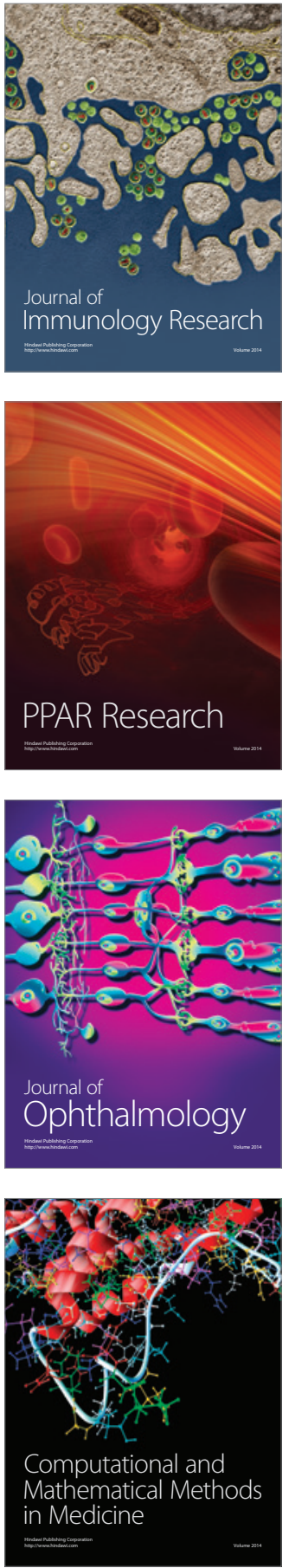

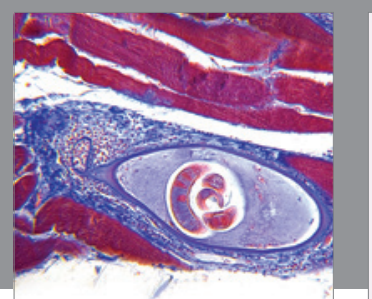

Gastroenterology Research and Practice

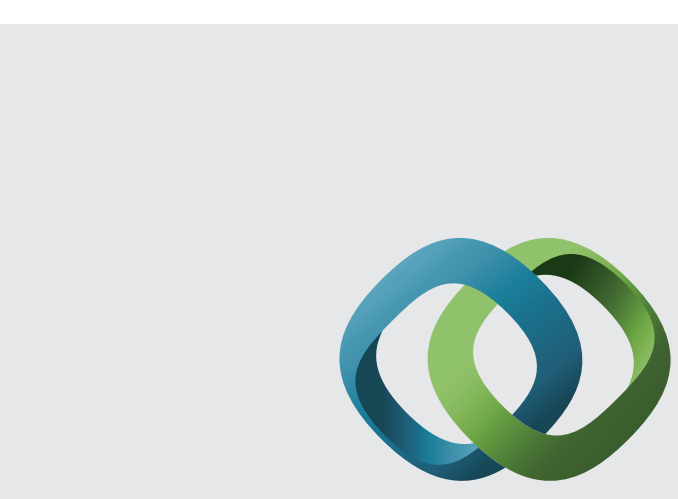

\section{Hindawi}

Submit your manuscripts at

http://www.hindawi.com
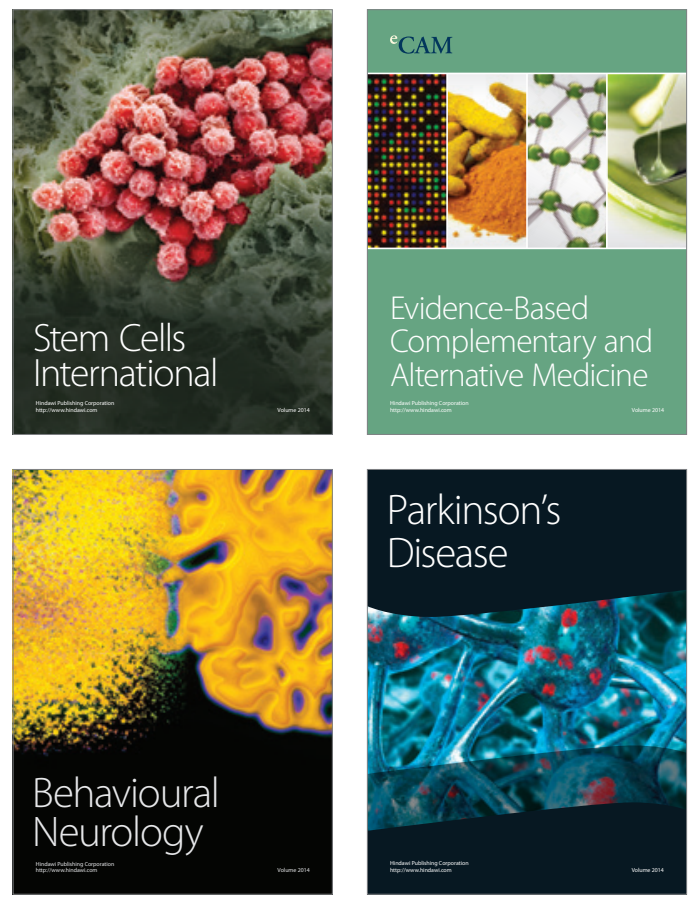
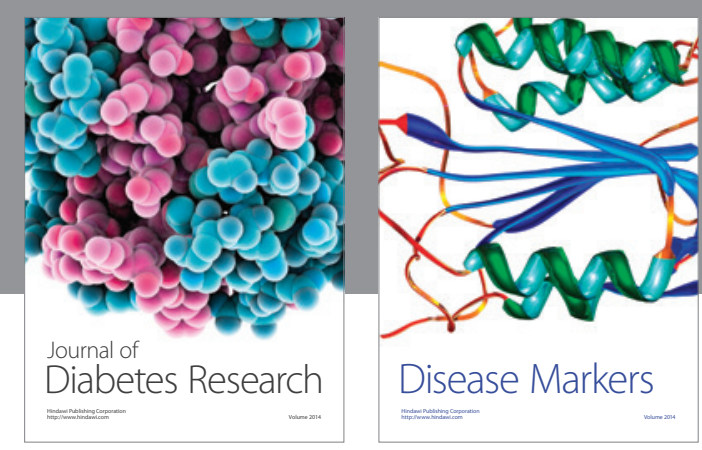

Disease Markers
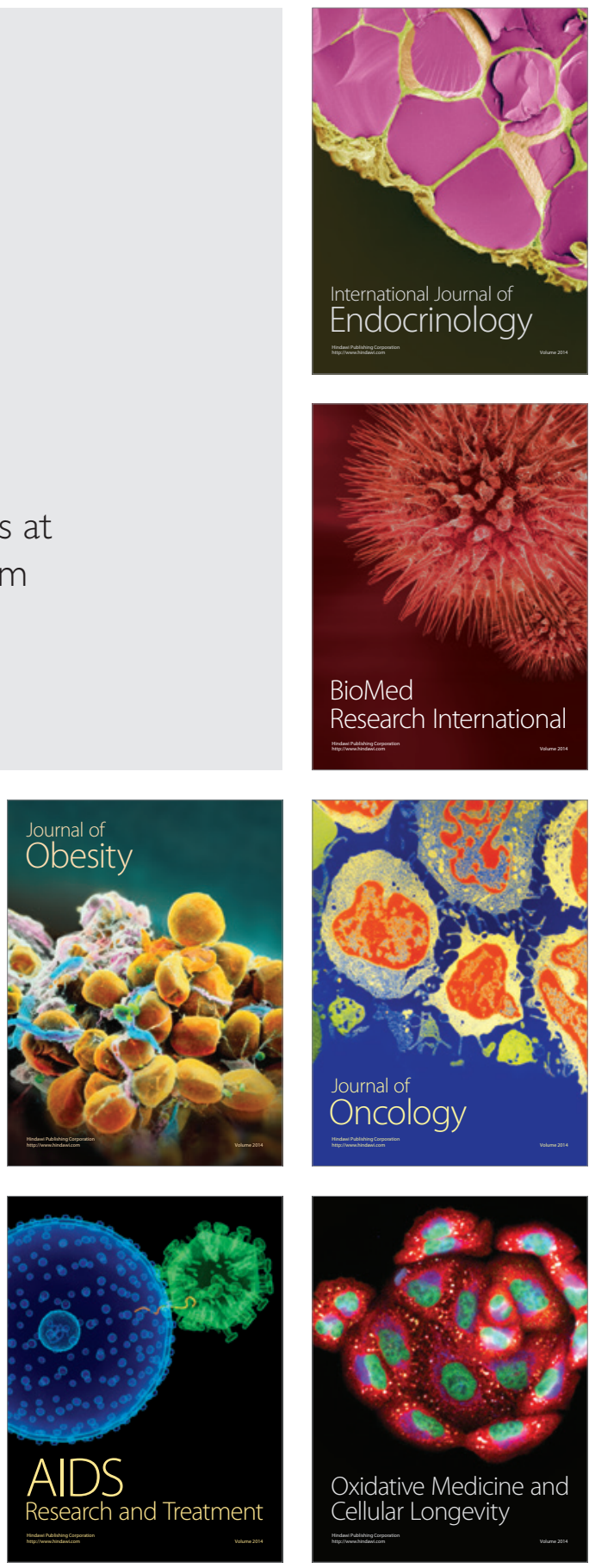